\title{
Flood fatality hazard and flood damage hazard: combining multiple hazard characteristics into meaningful maps for spatial planning
}

\author{
K. M. de Bruijn, F. Klijn, B. van de Pas, and C. T. J. Slager \\ Deltares, Boussinesqweg 1, 2629 HV Delft, the Netherlands \\ Correspondence to: K. M. de Bruijn (karin.debruijn@deltares.nl)
}

Received: 08 December 2014 - Published in Nat. Hazards Earth Syst. Sci. Discuss.: 05 January 2015

Revised: 28 May 2015 - Accepted: 03 June 2015 - Published: 22 June 2015

\begin{abstract}
For comprehensive flood risk management, accurate information on flood hazards is crucial. While in the past an estimate of potential flood consequences in large areas was often sufficient to make decisions on flood protection, there is currently an increasing demand to have detailed hazard maps available to be able to consider other risk-reducing measures as well. Hazard maps are a prerequisite for spatial planning, but can also support emergency management, the design of flood mitigation measures, and the setting of insurance policies. The increase in flood risks due to population growth and economic development in hazardous areas in the past shows that sensible spatial planning is crucial to prevent risks increasing further. Assigning the least hazardous locations for development or adapting developments to the actual hazard requires comprehensive flood hazard maps. Since flood hazard is a multi-dimensional phenomenon, many different maps could be relevant. Having large numbers of maps to take into account does not, however, make planning easier. To support flood risk management planning we therefore introduce a new approach in which all relevant flood hazard parameters can be combined into two comprehensive maps of flood damage hazard and flood fatality hazard.
\end{abstract}

\section{Introduction}

In many parts of the world, flood hazards are increasing due to climate change and subsidence. In addition, the vulnerability of societies is increasing significantly due to fast socio-economic developments. These socio-economic developments, such as population growth and economic development, are considered to be the main causes of the increased flood risk in the world during the last few decades (EEA,
2012; IPCC, 2012). Thus, to prevent a further increase in flood risks, not only should flood mitigation (e.g. flood protection or room for the river) be considered, but also a further increase in vulnerability in flood-prone areas should be avoided as much as feasible by sound spatial planning and adapted development in particular. To be able to fully take flood hazards into consideration in development planning, clear and meaningful information on the degree of flood hazard (now and in the future) is needed. Spatial planners could then decide to restrict building in some areas, to stimulate the deployment of certain adaptive measures, or to develop only in the most suitable (e.g. least hazardous) areas. For such spatial planning decisions hazard maps are more appropriate than maps of actual risk, as the latter take into account the already present people and property. Flood risk maps are obviously the most relevant for making decisions on reducing actual risk as caused by past decisions on land-use development, usually by improving some kind of flood protection, but for preventing the increase of risk as a consequence of land-use development awareness of the flood hazard is crucial. Hazard maps are not only required to enable spatial planning to become fully integrated in comprehensive flood risk management, they are also relevant for flood emergency managers and to create awareness among the general population (De Moel et al., 2009).

In this paper we define flood hazard as the potential to cause harm (Samuels et al., 2009). The hazard at a certain location depends on the probability of flooding and flood characteristics such as potential flood depth, flow velocity of the flood water, and speed of onset of a flooding. Hazardous areas are usually characterised by either a larger probability of flooding or more severe floods. We define flood risk as the combination of flood hazard and vulnerability. The vulnera- 
bility of an area is determined by characteristics such as the land use, the number of buildings and the type of buildings, and the number of people. Risk can be expressed by quantitative indicators such as expected annual damage or expected number of fatalities per year.

Although flood hazard mapping has been practiced for decades, the launching of the European Directive 2007/60/EC on the assessment and management of flood risks (the so-called Floods Directive) in 2007 boosted the making of flood hazard maps in all EU countries. This Directive requires member states to assess which areas are at risk from flooding, to map the flood extent and assets and humans at risk in these areas, and to take adequate and coordinated measures to reduce the flood risk where appropriate. Against this background, the member states formed a network to exchange experiences and executed the EXCIMAP project, which provided guidance on terminology and mapping practice and produced an atlas with many examples of hazard maps of EU countries (EXCIMAP, 2007a, b). Most EU countries have made maps which show values for one or two hazard characteristics, such as water depth maps for a certain recurrence time, e.g. the flood depth once in 100 years. Information on other characteristics, which may also be relevant, is then not visible. It is, however, very difficult to combine more than two parameters on one map in a simple way (De Moel et al., 2009).

Usually, flood hazard maps represent areas that are not protected by flood defences. However, since the flood hazard in areas which are protected by embankments may also be substantial and may differ significantly from one place to another, hazard maps for protected areas are relevant as well. Especially as flood defences may fail and cause large damage and a loss of lives.

Combining different flood characteristics is easier in natural river valleys without flood protection than in protected areas, because in such valleys there is a correlation between elevation, flood probability and potential flood depth. However, in areas protected by flood defences, this correlation is absent. In protected areas, areas which are flooded most deeply are thus not necessarily the most dangerous, since flooding may be very rare at those locations. Which area is most hazardous then depends on how hazard is exactly defined.

Therefore, we developed a new generic approach which enables the use of all hazard determining parameters both in areas protected by flood defences and in unprotected areas. We compose hazard maps by combining all relevant parameters into two new meaningful parameters: the flood damage hazard (FDH) to represent the potential of floods to cause damage and the flood fatality hazard (FFH) to represent the potential of floods to cause fatalities. Since these indicators potentially take into account all relevant parameters, hazard maps made for different kinds of floods from, for example, different sources, can easily be combined and at least become directly comparable. It is thus possible to combine hazard maps for floods from, for example, regional watercourses, main waterways, and for protected and unprotected areas. In fact, even hazard maps for hazards other than floods (e.g. storms or earthquakes) could be added and become comparable in a similar way. This helps policy makers to obtain a better understanding of which areas are more hazardous than others.

This paper first discusses previous hazard mapping attempts, then explains our flood hazard mapping approach which is subsequently illustrated by applying it to the case of the Netherlands. A discussion and conclusion round it off.

\section{Previous hazard-mapping attempts}

Because of the increased attention for flood consequences and measures that could reduce flood impacts, flood hazard mapping also gained increased attention in the past decades (De Moel et al., 2009). This increased attention was triggered both by the increase in flood losses in the last decades (EEA, 2012; IPCC, 2012) and by the recognition that flooding cannot be fully banished. To mitigate this steady increase in flood consequences, the EU issued the Floods Directive which required EU member states, among other things, to map hazards and risks by December 2013 - more specifically, maps of potential water depth, flow velocities, and flood probability. Various countries, such as Belgium, England, and Wales not only produced the required maps, but also combined two flood hazard parameters and developed maps showing, for example, the product of depth and velocity (EXCIMAP, 2007b). Other countries, such as Germany, Switzerland, the UK and the Netherlands combined different characteristics into a degree of hazard based on a (qualitative) classification (EXCIMAP, 2007a, b). These can be regarded as first attempts to combine different flood characteristics into a more comprehensive expression of flood hazard. The indication is, however, still rather descriptive and not directly aimed at a certain decision making problem or a specific target group. No examples were found of maps that attempted to show more than two flood hazard parameters simultaneously. Flood hazard in areas protected by embankments was usually found to be neglected entirely.

In the Netherlands, the Floods Directive induced the making available of the summarised outcome of many hundreds of flood simulations in the form of a composite hazard map (www.risicokaart.nl), which shows the maximum water depth as a result of the breaching of primary defences during design conditions at any location in the country (Slager and Van der Doef, 2014). In this context, many other maps were constructed based on the same simulations, e.g. flow velocity, time of first arrival, flood duration, source of flooding, etc.

During these years the Netherlands' government became more and more interested in possibilities to take into account flood hazard in spatial planning, especially since eco- 


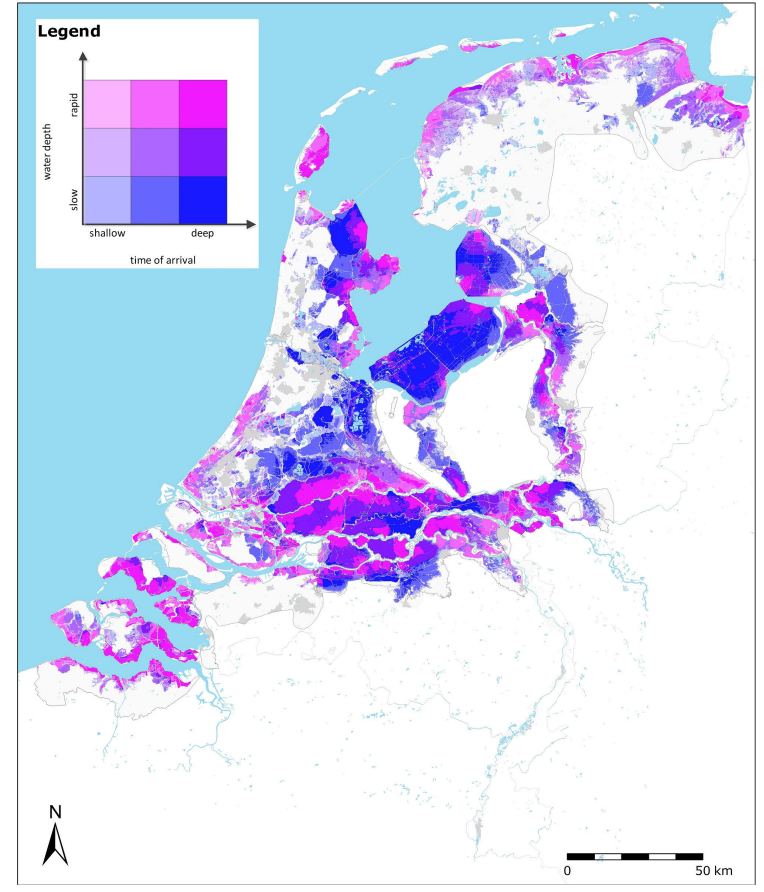

Figure 1. Flood hazard map related to water arrival time and water depth made according to the approach used in PBL (2009).

nomic growth in hazardous locations was found to be the factor which contributes most to the increase of flood risk and not climate change (Klijn et al., 2012). In this context, the Netherlands' Environmental Assessment Agency (PBL, 2009) attempted to combine the available flood parameter maps into relevant flood hazard maps. They categorised the area into hazard classes based on maximum water depth and arrival time and proposed building restrictions and recommendations for those. A number of other relevant parameters, such as flood probabilities, duration of flooding and water level rise rate were not taken into account. Their map only shows hazards in protected areas (see Fig. 1).

Thus, the approach by PBL (2009) does not give a full picture of the flood hazard from the main waterways since flood probability, flood duration, and water level rise rate are neglected. Moreover, this approach does not allow for gaining a full overview of flood hazards from regional water courses and main waterways, let alone pluvial floods, since the variability in the neglected parameters is too large. If these parameters would be included in the matrix also, it would become three- or multi-dimensional and thus way too complex. Another approach is thus needed to make a map that reflects flood hazard in a comprehensive way and can include different types of floods.

A first approach to develop a method to arrive at comprehensive flood hazard and flood risk maps for the Netherlands has been proposed by De Bruijn and Klijn (2009), who mapped risky places, i.e. places where many fatalities may be expected due to flooding, because they are both hazardous and vulnerable. Their maps attracted a lot of attention from policy makers and their advisory committees (e.g. the Delta Committee, 2008). To identify hazardous places, De Bruijn and Klijn (2009) identified the most important flood characteristics for the occurrence of flood fatalities and made indicative maps for those characteristics. They then combined them into a degree of hazard between zero and one. Their proposal was explicitly a first approximation and limited to flood fatality hazard. The present paper can be considered as an elaboration building on the ideas of De Bruijn and Klijn (2009) and complemented by also addressing flood damage hazard. This second approximation has become possible due to the vast amount of flood simulation results that have become available recently.

\section{The new flood hazard mapping approach}

Flood hazards can be characterized by flood probabilities and flood characteristics such as flow velocity, rising rate, maximum water depth, flood duration, and their combinations. It is not always straightforward to combine the maps of these different flood characteristics into one hazard value, since the individual characteristics are not always nicely correlated. Furthermore, the definition of hazardous is relative and case-specific: what area is most hazardous: an area with a flood probability of once in 100 years and a potential water depth of $1.5 \mathrm{~m}$, or an area with a flood probability of once in 1000 years and a potential water depth of $4 \mathrm{~m}$ ? A more objective measure of hazard is thus desirable.

To overcome these difficult classification and combination issues, we combined the various flood characteristics into two comprehensive hazard parameters: for fatality hazards we calculate the flood fatality hazard (FFH) and for damage hazard the flood damage hazard (FDH).

To this end, we used existing damage and mortality functions which provide the percentage of the maximum damage and the mortality rate as a function of all the relevant flood parameters. For each location we assess this damage factor and mortality rate for a whole range of probabilities and from this we calculate the expected annual damage fraction and the annual probability of death due to a flooding for each location, irrespective of the actual land use. Such damage and mortality functions are available for many countries (for the UK see Penning-Rowsell et al. (2005); for the Netherlands see Kok et al. (2005); for Germany see Kreibich et al. (2010) and for the USA see FEMA (2009)). These functions capture the best knowledge available on damage and mortality related to floods and thus may be assumed to include all relevant parameters and to reflect their combined effect of flood damage and mortality. Generally, these functions are used for flood consequence modelling in the context of flood risk assessments, for which information on the actual land use, inhabitants and objects in the flood-prone area are used in or- 
der to calculate potential damage and numbers of potential fatalities. Since we aim to develop hazard maps and not risk maps, we are not interested in the actual land use or number of objects present, nor in the actual presence of people, as we do not make this combination. Instead, we assume a standard hypothetical land use type and the presence of a hypothetical person.

One of the advantages of using damage functions and mortality functions for the production of hazard maps is that the maps of different kinds of floods and for different areas can be added up and can be directly compared, since the meaning of the values on those maps are identical, i.e. in the same value units. Flood hazard maps, whether of unprotected floodplain areas or areas protected by flood defences, whether or not related to coastal flooding or river flooding, can all be added up easily to one nationwide flood hazard map because the differences between these areas or sources are captured in the damage fractions or mortality rates (or evacuation possibilities). This advantage, of course, only holds if the flood damage functions and mortality functions take into account all relevant variables, or if different functions for different areas are used to reflect the effect of the non-included variables.

The damage and mortality functions should be applied to the whole study area, irrespective of the actual land use or population. Thus, map results show - in line with the definition of hazard - the potential for harm, i.e. to cause damage to buildings if they would be present there, or the danger of drowning at a certain location (if someone would reside there). We distinguish between damage hazard and fatality hazard because these rely on different functions and hence require different information. People can evacuate or flee, houses cannot. But the distinction is also made since both are needed by different policy makers. Flood emergency managers may be more interested in flood fatality hazard, while spatial planners might be interested in both flood fatality hazard and flood damage hazard. In the Netherlands, the flood fatality hazard has also been used in the recent proposal for a revised flood risk management policy comprising new flood protection standards: for equity reasons the government aims to ensure that not a single inhabitant of a protected area has to face too high a flood fatality hazard. Even in sparsely populated areas where economically optimal flood protection levels are low, flood risk reduction measures may be implemented to ensure that the flood fatality hazard does not become unacceptably large (Beckers et al., 2012; Van der Most et al., 2014).

\subsection{Flood fatality hazard map}

FFH maps indicate which locations are more life-threatening than others. FFH is defined here as the probability of death at a certain location due to a flooding assuming continuous presence, but also taking into account the possibilities of evacuation when a flood is imminent. In the Netherlands

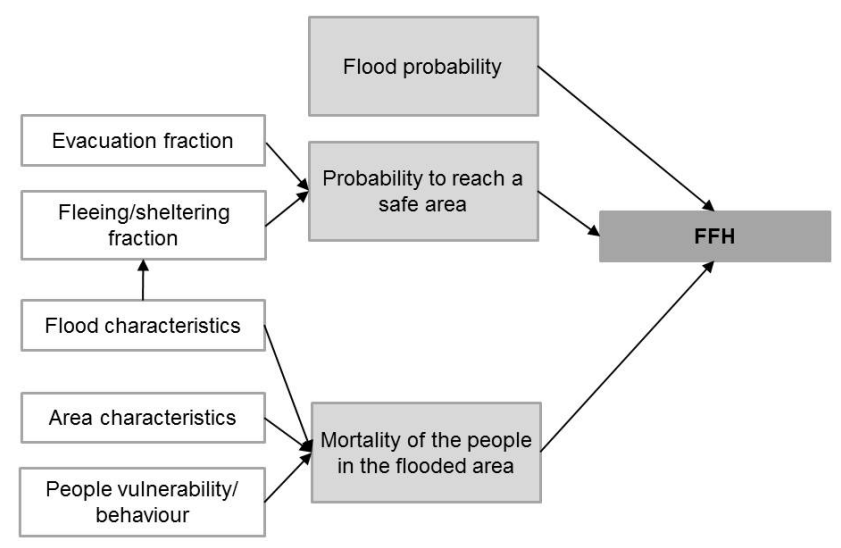

Figure 2. Overview of parameters influencing the flood fatality hazard.

this FFH is often called LIR: local individual risk. We prefer to call it hazard, because it assumes hypothetical persons instead of taking into account an individual's true behaviour and presence, and because it also applies to uninhabited areas. If the FFH would be combined with a population density map, flood fatality risks would be obtained.

To obtain the FFH all relevant factors which determine the probability of death at a certain location due to a flooding must be considered. De Bruijn and Klijn (2009) gave an overview of factors that influence the fatality hazard and fatality risk based on a literature review on three approaches: an expert judgement approach, the flood risk to people approach (HR Wallingford, FHRC and Risk \& Policy Analysts, 2006), and an approach using flood mortality functions (Jonkman, 2007).

The last one is incorporated in the Dutch standard damage and fatality model (Kok et al., 2005). All three methods consider flood hazard parameters such as water depth to estimate flood fatalities. The risk to people method also includes parameters such as building type and differences in the vulnerability of individual people. In the other two methods, which were designed for large-scale studies, these factors are taken into account implicitly, or deliberately neglected. Based on their analysis, De Bruijn and Klijn (2009) decided to make hazard maps with a hazard rating based on combinations of the parameters flood probability, water level rise rate, and water depth. They also assessed a vulnerability rating based on an analysis of the population density of an area and the suddenness of flooding as an indicator of the possibility of reaching safe areas in case of flooding. The vulnerability and hazard rating were then combined in order to find risky places. Their approach was qualitative: they rated all parameters between zero and one and combined them into a new value between zero and one. 
Now, we follow a quantitative approach and combine the relevant parameters into the FFH. In the first instance, the FFH depends on three main factors (see Fig. 2):

1. the probability of flooding;

2. the probability that people can reach a safe location before the arrival of the flood water;

3. the probability of death due to the drowning of those people who could not get away in time.

We thus combine flood hazard parameters and parameters related to the possibility of reaching safety in the hazard map. De Bruijn and Klijn (2009) related evacuation and fleeing to a vulnerability rating and did not include this in their hazard map. We now thus use a slightly different approach in order to make the map more useful for spatial planners and emergency managers. As it is more dangerous to be in an area from which it is difficult to get away in time, such areas may require extra attention in planning and be considered more hazardous.

The elaboration of these parameters and the choice on how to incorporate them may have to be different per region. For all regions the maps must include the most important parameters. The probability of flooding depends on, amongst other things, the elevation of the area, the probability of failure of flood defences if present, and the expected flood patterns when they fail.

The probability to reach a safe location depends on the evacuation and fleeing possibilities. We distinguish evacuation from fleeing. We suppose that evacuation occurs before the onset of the flooding: the precise flood location is not known yet and a large area is to be evacuated. Fleeing occurs during the flood event, mainly from areas which have not yet been flooded. The available time for fleeing depends on the water arrival time measured from the onset of the flooding and the success of the fleeing also on the time needed to reach a safe location. The evacuation possibilities depend on the available time for evacuation and on the time needed for evacuation. The available time depends on the hazard source: storm surges are generally more difficult to accurately forecast than floods in lowland rivers, and thus have shorter forecast lead times. Floods due to non-closure of storm surge barriers cannot be forecasted in advance at all. The time needed for both evacuation and fleeing is influenced by the population density, road capacity, distance to safe areas, weather conditions, and so on.

The mortality of people present in the area during the flood event depends, among other things, on the severity of the flooding, the behaviour of the people, and the height and strength of the houses. The severity of flooding is described by parameters such as water depth, water flow velocity, and so on. The behaviour of the people depends on their preparation and experience, knowledge of the area, age, health, and the quality of information and support provided. The height

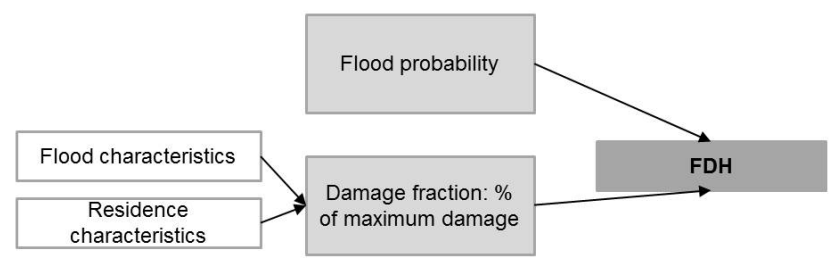

Figure 3. Overview of the parameters included in the flood damage hazard.

and strength of the buildings determines whether people are safe within their homes. If houses do not collapse and have a second or third floor, people are likely to survive multiple days before being rescued. For the region under consideration a specific flood mortality function is required which relates the most relevant flood parameters to mortality. For the Netherlands, the Dutch standard mortality functions may apply (see next section).

Many areas are threatened by various flood events resulting from different breach locations with different probabilities and different associated flood pattern. The FFH of a location $x$ is then calculated by multiplying the scenario probability $P_{i}$ with the fraction of the number of inhabitants present in the flooded area and the flood mortality rate $F_{\mathrm{D}, i}$ of those people for each flood scenario $i$ and then calculating the total value over all scenarios. The fraction of the inhabitants present in the flooded area depends on the evacuation fraction $f_{\text {evacuation }}$ and the flee fraction $f_{\text {fleeing }}$ (see equation 1 ):

$\operatorname{FFH}(x)=\sum_{i} P_{i}\left(1-f_{\text {evacuation }}\right)\left(1-f_{\text {fleeing }, i}\right) F_{\mathrm{D}, i}(X)$.

\subsection{Flood damage hazard map}

The second hazard map made shows the flood damage hazard (FDH). The flood damage hazard is the annually expected percentage of the maximum damage of residences. For damage hazard the flood probability and damage fraction, which is determined by the flood severity and building characteristics, are most relevant (see Fig. 3). The available time or suddenness of a flooding are less relevant since it is difficult to move objects out of the flood-prone area. Although the removal of vehicles and cattle, the installation of furniture upstairs and the installation of emergency measures is possible, we do not yet take this possibility into account in our calculations for the damage hazard map. Damage is usually primarily determined by damage to buildings and companies and these cannot be moved to safe places easily.

The flood probability has already been discussed in the previous section on FFH. The damage fraction, which is the percentage of the maximum damage that may occur due to flooding, depends on water depth and other flood severity parameters (Fig. 3). Flow velocity is relevant only when it is large enough to cause extra damage or collapse, which 
is generally only the case in sloping areas, very close to breach locations, at restrictions or in areas with significant tidal ranges. Flood duration may also be an important parameter, since it influences the recovery duration, which, however, also depends on numerous other factors such as the flood extent, the type of damage, damage in the surroundings (roads, utility services etc.), funds available, etc. Finally, parameters such as waves, debris, and water quality may be relevant damage determinants in some cases.

The damage fraction also depends on the characteristics of the assets: road damage is less influenced by flood depth than damage to residences, for example. The relationship between flood characteristics and damage is reflected in asset-specific damage functions which give the percentage of the maximum possible flood damage for each flood intensity value (e.g. water depth). We propose to use the damage function for single-family houses for the FDH map, since damage to residences firstly often forms the majority of an area's flood damage whereas this damage function secondly is also the best validated, and it thirdly is a good mean function for general purposes. However, if one were specifically interested in the FDH for certain types of industry or other specific assets, the damage function for these might be used.

To map the FDH for location $x$, for each flood scenario $i$ the fraction of the maximum damage $V_{\mathrm{D}, i}$ which residences would have if they were located there, is calculated. This damage fraction is multiplied with the flood probability or scenario probability $P_{i}$. Finally, the contribution of all flood scenarios is added to obtain the total FDH (see Eq. 2). This is done for each location (all cells) in the area, no matter whether there are non, a few or many houses present. The FDH map shows where houses would likely suffer significant flood damage if there were houses developed on that location.

$\operatorname{FDH}(x)=\sum_{i} P_{i} V_{\mathrm{D}, i}(X)$.

\section{Application to the Netherlands}

\subsection{Area description and approach}

The approach has been applied to the Netherlands. The Netherlands is threatened by flooding from the sea, from large rivers, from lakes, and from regional waterways (drainage and irrigation canal system). This paper combines flood hazards related to floods from the sea and estuaries, the Rhine and Meuse rivers and Lake IJssel only. Floods in protected and in unprotected areas are both considered. Floods from regional waterways are, however, not yet included because of insufficient data coverage when we produced the map.

In order to develop the hazard maps, first the individual flood characteristics were mapped and the evacuation possibilities were identified. Then the FFH and FDH were made by translating the flood characteristics to damage fractions and mortalities based on damage functions and mortality functions respectively, and multiplying those with the flood probability. For the FFH the evacuation possibility was also taken into account.

For the mapping of the individual flood hazard parameters we used as many flooding simulations as possible. A large set of flooding simulations has become available from the national FLORIS project (Jongejan et al., 2011). This set of simulations corresponds with a set of representative breach locations, which were selected in such a way that they give insight to all potential flood scenarios. The choices made to select breach locations and parameters for breach growth, the reliability of secondary embankments, hydraulic roughness, etc. are discussed by Kok and Van der Doef (2008). We use those simulations which correspond with design hydraulic loads: water levels and river discharges on which the current design of the embankments is based. These design loads' probability differs per region: for riverine areas it varies between once in 1250 and once in 2000 years. For the coastal areas it varies between once in 4000 and once in 10000 years.

For the unprotected areas we do not have a set of flood scenarios, but instead we used water depth maps for floods with a probability of once in 10 , once in 100 , and once in 1000 years (Slager and Van der Doef, 2014).

The flood simulations were used to derive maps of water depth, water level rise rate, and arrival time for the Netherlands as a whole. The generated maps have a cell size of $25 \times 25 \mathrm{~m}^{2}$, quite adequate for spatial planning purposes. Flow rates in the Netherlands are, generally, very low, except near a breach. We therefore excluded this parameter from this analysis.

This section first discusses the mapping of some individual flood parameters and next the FFH and FDH maps.

\subsection{Mapping flood parameters}

\subsubsection{Flood probability}

For areas not protected by the primary defences, the flood probability is easily derived from the water level at which first flooding occurs. However, for the areas protected by flood defences, flood probabilities depend on failure probabilities and these are uncertain and difficult to establish (Jongejan et al., 2011). This probability depends on a number of possible failure mechanisms, related to both loading and the strength of the embankment, and may differ substantially from the legal protection standard. Flood probabilities in protected areas depend not only on the failure probabilities of the defences, but also on the flood patterns. These flood patterns are influenced by the external flood level and the elevation of the protected area including the many linear elements which affect the flooding process. 
In this paper we use the failure probability as estimated for 2015 after a number of major flood mitigation projects have been finished (Van der Most and Slootjes, 2014). The failure probabilities of the defences are translated to flood probabilities by linking them to flood patterns. Areas which may become flooded due to breaches at different defence sections obtain a flood probability equal to the sum of the failure probabilities of those sections.

Figure 4a shows that the flood probabilities are largest in the unprotected floodplain areas and in the protected alluvial plains along the large rivers. They are smallest in the densely populated coastal areas (and nil of course on high ground).

\subsubsection{Water depth}

Figure $4 \mathrm{~b}$ shows the possible maximum flood depths. For the unprotected areas, water depths are shown for a probability of 1/1000 per year. For the protected areas, the maximum value found in any of the used flood scenarios is shown. The figure shows that potential flood depths are largest in the central river area, the reclaimed polder areas around Lake IJssel and in small reclaimed areas near Rotterdam and in the southwest and north-east. The variation in potential water depths in the unprotected areas is large: the natural tidal marshes flood deeply, while the harbour and industrial areas are generally raised and hence have to cope with very small water depths only.

\subsubsection{Water level rise rate}

Figure 5a shows for each hectare the maximum water level rise rate over the first $1.5 \mathrm{~m}$ of water depth found in any of the flood simulations. It shows high water level rise rates in the small polder areas just behind the main embankments near Rotterdam, in the south-western part of the country and in the north. Also just upstream of secondary embankments along the rivers water levels may rise much faster than elsewhere. These areas with a high water level rise rate may be more dangerous, especially if the arrival time of the first water is also short. People may then be surprised by the fast coming and rising water and may become trapped. Water level rise rates in unprotected areas are generally very low, as the Netherlands does not experience flash floods.

\subsubsection{Water arrival time}

Figure $5 \mathrm{~b}$ shows the minimum arrival time found in any of the flood simulations. It is measured from the moment of breach initiation until the water reaches a depth of $2 \mathrm{~cm}$. Unfortunately, the water arrival time map is very sensitive to the choice of the potential breach locations, as is clearly visible in the reclaimed areas around Lake IJssel. Near the breach locations water arrival times are very short. Since breaches may occur anywhere along the embankments, short water arrival times should be visible as a zone along the embankment instead of just near the somewhat arbitrary breach locations.
Thus, this map is indicative only. It does, however, clearly show that in some areas the water arrival time is much longer than $24 \mathrm{~h}$. This is significant as it gives ample time to flee. In unprotected areas, the water arrival time is not a relevant parameter. There, the possibility of the inhabitants leaving the area in time depends entirely on whether a flood can be forecasted in time. Therefore, arrival time is not mapped for the unprotected areas.

\subsubsection{Other parameters}

Flooding in the unprotected areas usually lasts about as long as the duration of the high water level in the river or at sea. For storm-driven events this duration is short (hours to days); for river floods the duration may be longer than a week. Floods resulting from dike breaches normally last much longer (from a week to many months). The effect of flood duration on fatality rates is expected to be small. Although floods may last for weeks, it is assumed that people are rescued after some time. A flood's duration may, however, affect the damage. This was neglected in our calculations so far.

Other parameters such as the occurrence of waves, pollution, and debris may be important for both damage and fatalities at some locations and irrelevant at others. Since we do not have information on these parameters, however, and because they are very case-specific we have neglected them as well.

\subsubsection{What do the maps tell us}

The maps in Figs. 4 to 6 give different impressions on which areas are hazardous. The central riverine area stands out both in the flood probability and water depth map and is thus clearly more hazardous than the coastal areas. Some small polder areas near Rotterdam have very small flood probabilities, but very large depths, high water level rise rates and short water arrival times. Thus, floods there are rare, but deadly. In the unprotected harbour areas near Rotterdam, flood probabilities are generally much larger than in the protected areas, but flood depths are much smaller. These are relatively safe places.

Which area is more hazardous depends on how hazardous is defined: for emergency planners the areas with large flood depths and high water level rise rates may be most relevant, while for new housing developments or the construction of new infrastructure areas with a large flood probability are most relevant to identify. It is thus not sufficient to consider only one hazard parameter, but instead, all relevant flood parameters must be considered together and their interpretation must be linked to the needs of the decision maker.

\subsection{Combining parameters to flood fatality hazard}

To assess the flood fatality hazard we need the flood probability, the probability that people reach safe locations in time 
(a)

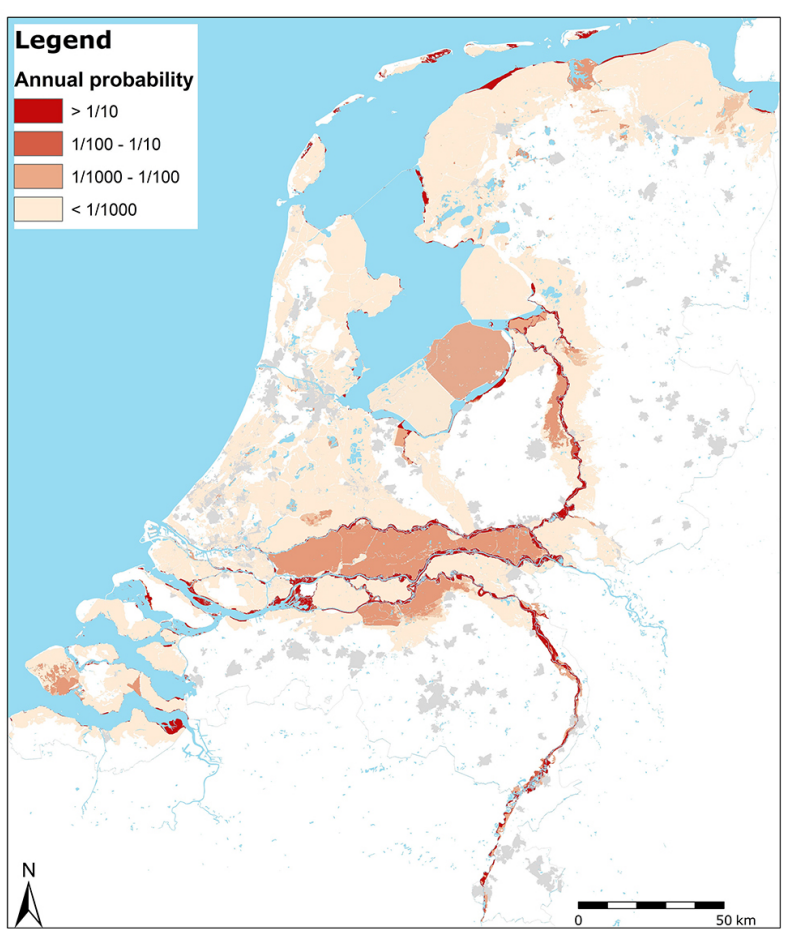

(b)

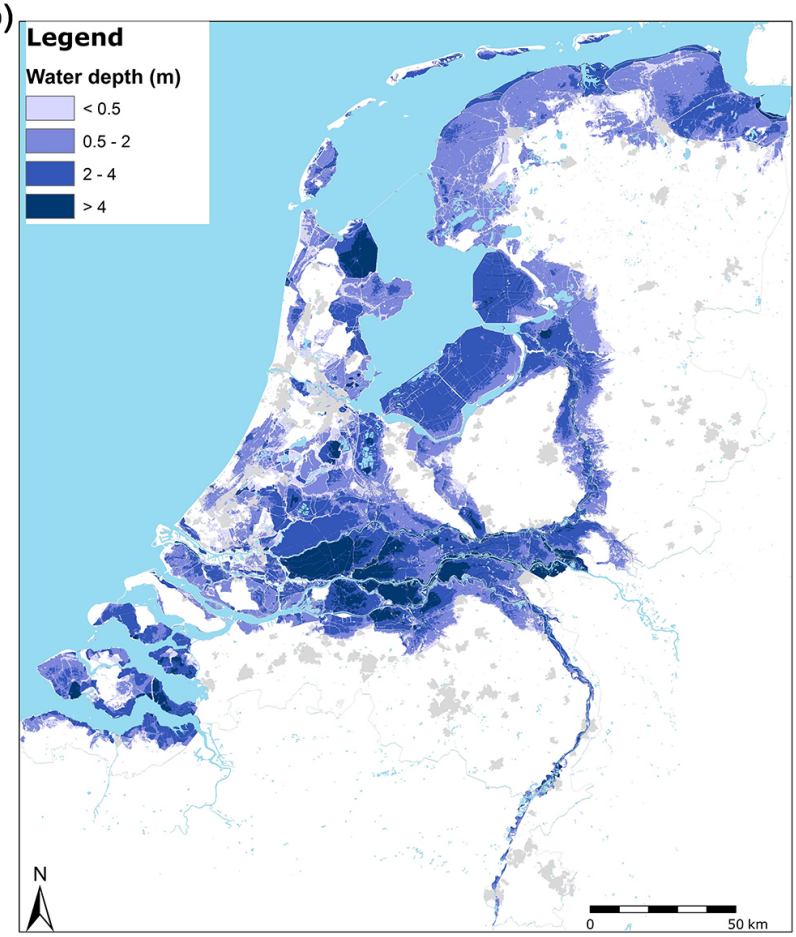

Figure 4. Flood probabilities (a) corresponding with floods from the main waterways for the situation in 2015 (DPV 2.2, 2014) (left) and water depths (b) corresponding with floods from the main waterways at design conditions (right).

(a)

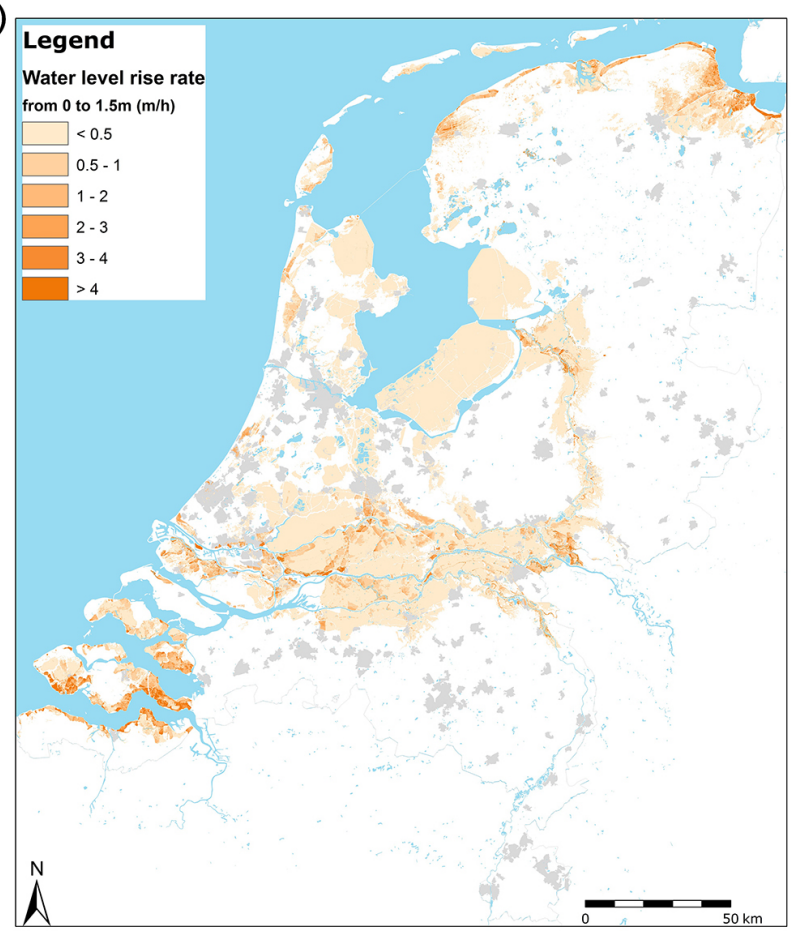

(b)

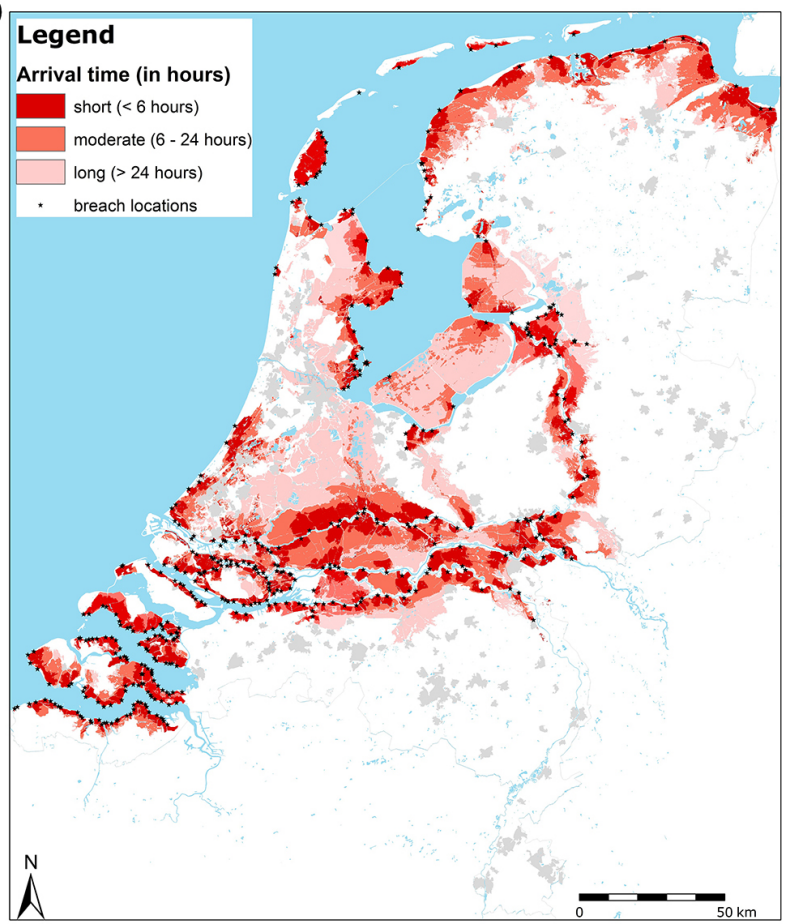

Figure 5. Water level rise rate (left) and minimum time of arrival found in any of the flood simulations (all corresponding with design conditions) and the breach locations used (map only for the protected areas) (right). 


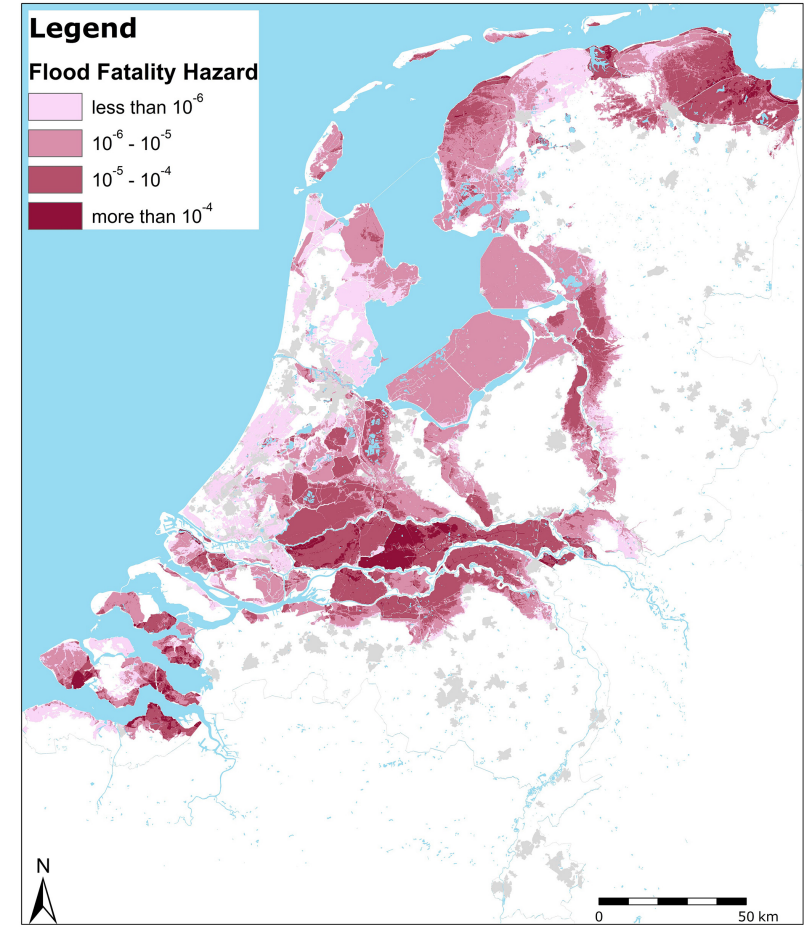

Figure 6. Flood fatality hazard (FFH) map related to floods from the main waterways. FFH is the probability of death due to a flooding taking into account evacuation possibilities in the Netherlands.

and the mortality of the people left behind (see Fig. 2). The flood probability is shown in Fig. 4 in the previous section.

The assumed evacuation success map was taken from Maaskant et al. (2009a). It provides an estimate of the percentage of the population which is expected to reach safety before the dike breaches. It is based on expert judgement on the probability that decision makers decide to evacuate 1,2 , 3 or 4 days before the flood event but also on the probability that a flood event occurs unexpectedly. Also, the probability that an evacuation is organized, normal or chaotic is taken into account and the fraction of the population which may reach safe areas is determined with traffic models. Evacuation possibilities are largest (75\%) in sparsely populated areas threatened by river flooding, and smallest in the densely populated islands threatened by storm surges $(15 \%)$. The possibility of fleeing after the dike breaches was not taken into account, although some areas may remain dry for days before the flood water arrives. Unfortunately, the water arrival time has not yet been included in the Dutch Standard Damage and Fatality Model and therefore we could not include it in this analysis. We have, however, established its relevance for fatality estimates (De Bruijn and Slager, 2013) and intend to build it in the next generation model.

The relationship between flood hazard parameters and mortality was obtained from the Dutch mortality functions. In the standard functions the mortality $F_{\mathrm{D}}$ is calculated based on the parameters flow velocity $(v)$, water depth $(d)$, and the water level rise rate over the first $1.5 \mathrm{~m}(\mathrm{dh})$ by using the formulae of Jonkman (2007) and the adaptations as discussed in Maaskant et al. (2009b) (see Eq. 2):

$$
\left\{\begin{array}{c}
F_{\mathrm{D}}=1, \mathrm{hv} \geq 7 \mathrm{~m}^{2} s^{-1} \text { and } v>2 \mathrm{~m} s^{-1} \\
F_{\mathrm{D}}=\Phi_{N}\left(\frac{\ln (h)-7.60}{2.75}\right) h<2.1 \operatorname{mord} h<0.5 \mathrm{mh}^{-1} \\
F_{\mathrm{D}}=\Phi_{N}\left(\frac{\ln (h)-1.46}{0.28}\right) h>2.1 \operatorname{mandd} h>4.0 \mathrm{~m} \mathrm{~h}^{-1}
\end{array}\right.
$$

where $\Phi_{N}$ is the cumulative standard normal distribution function. The first line is valid for locations near the breach zone or in other areas with very rapidly flowing water. The conditions for the first equation are very rarely met. The second line is valid in areas with a slow water level rise rate, the third line for locations with a very high water level rise rate. For all locations with rise rates between 0.5 and $4 \mathrm{~m} \mathrm{~h}^{-1}$ a linear interpolation between the second and third mortality function was made.

The mortality functions were derived from the 1953 flood disaster in the Netherlands, but are assumed to be still valid for the current situation in all areas protected by flood defences. The mortality functions were validated with data from Canvey Island (UK), which also flooded in 1953 (Di Mauro and De Bruijn, 2012; Di Mauro et al., 2012). The results indicate that the general pattern of fatalities and hazardous locations is reproduced rather well. However, the mortality function must always be used with care, since the 1953 disaster may not be representative of present-day floods. The functions do not yet explicitly reflect the effect of warning time, arrival time of the flood water, strength of houses, the behaviour of people, or communication possibilities. The effect of these factors is thus incorporated implicitly only. Because the effect of these factors may differ significantly from their effect in the 1953 flooding, the functions are less reliable for the current situation. Research to improve and update the mortality functions is ongoing (see e.g. De Bruijn and Slager, 2013).

Figure 6 shows the resulting FFH map for protected areas. For the areas not protected by flood defences we assume that everyone can reach safety in time. We did not calculate the FFH map for those areas.

The FFH in the areas protected by flood defences was found to vary between $10^{-4}$ and $10^{-7}$ per year. The highest values occur just behind breaches, and at locations where the water can rise quickly. Such locations are found predominantly in small enclosed areas or just upstream of embankments or other obstacles in sloping areas along the rivers. In some areas at large distance from primary flood defences, high FFH are calculated, while it is likely that the people there have sufficient time to leave before the flood water arrives. It is, therefore, considered essential to incorporate arrival time in the next FFH map. 


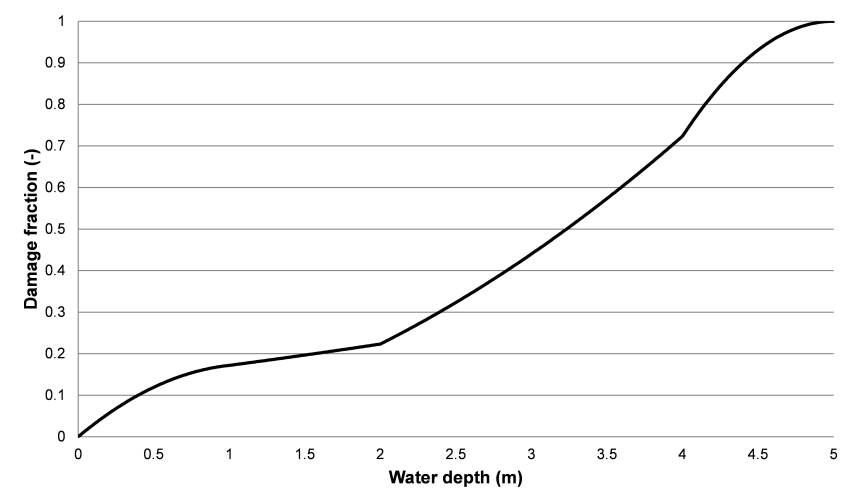

Figure 7. Damage function for single-family houses, which is used for aggregating the flood characteristics to the FDH map for the Netherlands.

\subsection{Combining flood parameters to the flood damage hazard}

The flood damage hazard is related to the yearly expected damage percentage of average Dutch houses (see Sect. 3.2). The damage factor is assessed for hypothetical houses based on the damage function for residential houses within the standard Dutch damage model (Fig. 7). The FDH map was made by calculating for each flood scenario the damage factor and multiplying this for each flood scenario with the probability. Finally, the results for all scenarios were added up to obtain the FDH as shown in Fig. 8.

Figure 8 also shows results for the unprotected areas. The FDH was calculated there based on depth maps for a certain probability of exceedance, since no flood scenarios were available for these areas. The damage factors corresponding with the once in 10 , once in 100 and once 1000 years depth map were assessed. If the damage fraction increases gradually with depth, then the exceedance probability $P$ of that depth can be plotted against the damage fraction. By integrating this relationship the annual expected damage fraction is obtained (Eq. 3).

$\mathrm{FFH}=\int_{0}^{1}$ Damage fraction $(P) \mathrm{d} p$.

The FDH map represents the likely yearly damage if the area were to be developed, independent of the current land use. The values vary between $10^{-2}$ and $10^{-4}$. An FDH value of $10^{-2}$ means that the expected annual damage of a development there amounts to $1 \%$ of the maximum flood damage. The map shows a strong correlation with the flood probability map but is also influenced by water depth. The highest FDH values are found in the downstream parts between the large rivers (Betuwe area), and in small deep compartments in the (south-)west of the country and just behind the embankments in the north.

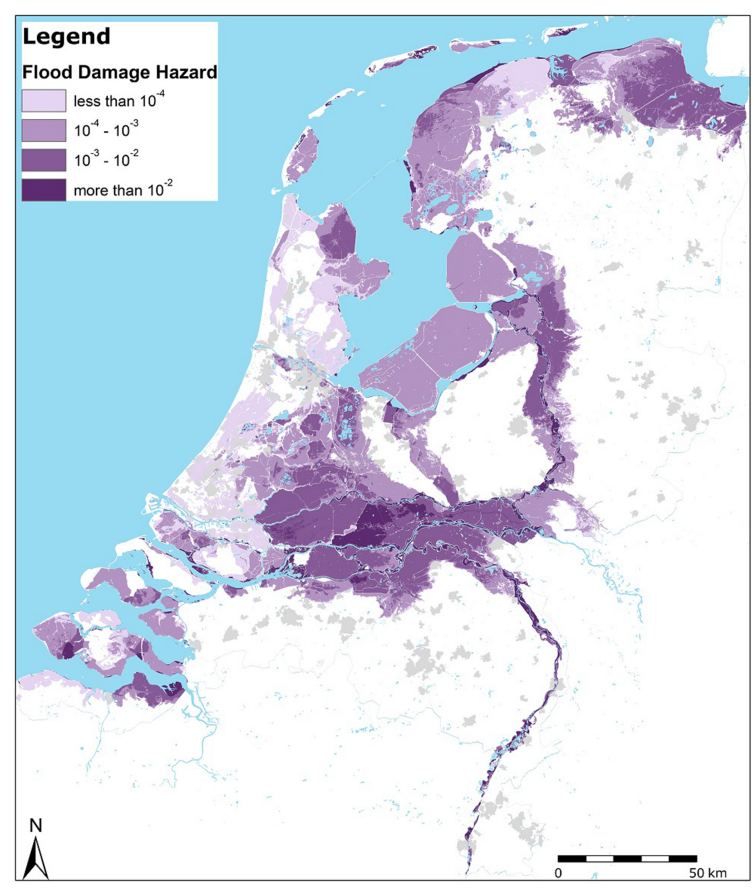

Figure 8. Flood damage hazard (FDH) map related to floods from the main waterways. The FDH map shows for each location the expected annual fraction of the maximum damage of residences if they would be present at that location.

\section{Discussion}

\subsection{On the produced maps and their sensitivity to assumptions}

The hazard maps are developed to support flood risk management, in particular through spatial planning and building regulations, i.e. aimed at preventing a future increase in risk and not at reducing actual risk. To this end the maps must be accurate, meaningful, complete, and at the right scale. The accuracy of the maps is obviously as good as the poorest accuracy of the input data, comprising flood probabilities, a number of flood characteristics, and damage/mortality functions. The uncertainties in the flood probabilities and damage/mortality functions are expected to be the largest. Flood probabilities are especially difficult to establish in protected areas, where they depend not only on exceedance probabilities of water levels, but also on the strength of the defences. The damage functions also contribute significantly to the uncertainty (Wagenaar et al., 2015). If the damage functions do not relate to the most relevant parameters, or have a shape which does not adequately reflect reality, the hazard maps will also be less accurate.

The FFH map made for the Netherlands in Sect. 4 is based on officially accepted flood mortality functions. These functions include water depth, flow velocity, and water level rise rate. However, recent research has revealed that the influence 
of the arrival time of the water may also be very relevant and this parameter is not considered. This means that for areas where the flood arrival time is long, the map could overestimate the FFH. It is, therefore, recommended to improve the standard mortality functions by including the effect of the arrival time. Furthermore, it is expected that the functions will be rather pessimistic since they are based on data of the 1953 flood event when many fatalities were due to the collapse of houses. Since the houses of today are much stronger and are expected to be able to survive prolonged flooding, fewer fatalities may occur these days in similar events. For more discussion on the mortality functions see Di Mauro and De Bruijn (2012), and De Bruijn and Slager (2013).

The maps shown in this paper are calculated for grid cells of $25 \times 25 \mathrm{~m}^{2}$. This resolution is sufficient for the protected areas, since the Netherlands is quite flat and water depth hence varies little in space, but it does not suffice for unprotected areas, where water depth varies over much smaller distances. If local measures are to be planned, more detailed information may also be required, especially in areas with many small obstacles and embankments in unprotected areas. The maps we presented in this paper are thus primarily applicable for planning at the regional scale, for example for large-scale new developments.

Future changes will affect the reliability of the hazard maps. The key flood characteristics, especially flood probability but also water depth etc., may change due to climate change or due to human interference, such as further dike strengthening. The evacuation success and fleeing possibilities may change due to improved warning and emergency management, or due to improvements in the road system. Furthermore, the mortality and damage functions may need updates due to, for example, enhanced preparedness or less susceptible building.

\subsection{On the wider applicability of the approach}

The approach to map hazards as discussed in this paper has been successfully applied in the Netherlands. It is, however, generic in character and hence applicable in other areas as well, as long as there are appropriate mortality and damage functions available and sufficiently accurate geographical data on the relevant flood characteristics.

The approach has added value above existing flood hazard mapping approaches, especially for areas with flood protection in place, because there the various individual flood parameters may give different or even contradictory signals about the degree of hazard. Damage and mortality functions then can serve as objectifying means to compare and combine the various parameters. The approach is, however, applicable to all flood types for which relationships between flood characteristics and mortality or damage exist.

In the application in chapter four for the Netherlands, the FFH map is based on combining four parameters (flood probability, flow velocity, water depth, and water level rise rate), but for the FDH map only water depth and flood probability were used to characterise flood hazard, (and the influence of flow velocity was found to be negligible). Information on other factors such as debris and flood duration is too difficult to incorporate or too difficult to map. However, for events with a short duration such as floods from regional waterways, the duration may be significant and must then be incorporated in the damage functions. The overall approach would not be affected by adding such extra parameters.

It is likely that the approach is not only applicable to flood hazards, but also to other natural hazards of which the impact may be expressed by damage functions which relate hazard characteristics to relevant outcomes such as damage to property or mortality of people. This might allow that the maps of different natural hazards can be combined into one overall hazard map. But it would at least make the impacts of different natural hazards comparable and it would enable planners to simultaneously take into account various relevant hazards in their plans.

\subsection{On the (potential) use of the flood hazard maps}

There is an interest in hazard maps from spatial planners, emergency managers and governments who desire to raise flood awareness. In spatial planning, land suitability analysis is a common approach for assessing which locations are most or least suitable for different land use functions. Flood hazard may be a relevant element of such a suitability analysis. Hazard maps as presented in this paper can easily be incorporated in simple GIS-overlay processing, more advanced (weighted) multi-criteria decision making methods and sophisticated land use development modelling which are used in this field. Flood risk management planners can use the hazard maps as a basis for hazard zoning on behalf of land use planning, to gain support for investments in adaptation measures, or for enhancing flood awareness among individuals or other authorities. Emergency managers may use the maps to direct their attention towards the most hazardous areas.

In the Netherlands there is a huge demand for hazard maps: they are currently being used in the Delta Programme both in support of spatial planning policy (Van de Pas et al., 2012) and also to derive flood protection standards in view of providing a basic protection level to everyone living in a protected area (Van der Most and Slootjes, 2014; Beckers et al., 2012). The flood fatality hazard map is currently also being used to define priority locations for emergency planning.

Two distinct hazard maps were proposed which combine the various flood intensity and flood probability parameters relevant for loss of life and damage respectively. Now there are areas which attract attention in both maps, because they have the potential to cause harm to both people and property. However, there are also areas which attract attention only in one of the two maps: areas with a large flood probability but shallow water depths are not fatal and show up only in the FDH map, but do not stand out in the FFH map. Areas with 
a small flooding probability but a very large water depth and rapid water level rise rate may, in contrast, qualify as being very hazardous from a fatality point of view, whereas the potential to cause damage is limited because of the small probability of flooding. These areas stand out clearly in the FFH map, but not in the FDH map. Since spatial planners may desire to distinguish between developing for large population densities (urban development) on the one hand and for infrastructure or industry on the other, they may be interested in either the flood fatality hazard map or the flood damage hazard map, or both. The maps are complementary to each other and useful by themselves. In support of a first signalling a combined hazard zoning map can be composed on the basis of both the FFH and FDH maps, as we proposed to the Netherlands' Delta Programme on New Development and Re-development (yet unpublished). However, the two hazard maps shown may also individually serve as signalling maps; after all, they primarily show which areas need special attention. The underlying maps on individual flood parameter can then be consulted next to identify why exactly a particular area is more hazardous (e.g. because of its rapid water level rise rate, its large flood probability, etc.). Measures may then be designed or adjusted in such a way as to account for the location-specific hazard profile.

The most difficult discussion, however, which is not settled yet in the Netherlands, is about which regulations to enforce in hazardous zones: restrictions on development or building codes? In various countries hazard maps or hazard zoning are already used to regulate spatial development. In Canada (Alberta), for example, building restrictions apply for floodways and flood fringes related to the $1: 100$ flood probability. In Australia building standards apply for building within the $1: 10$ year zone (ABCB, 2012). In the UK, development planning is being regulated through the National Planning Policy Framework (NPPF), which is supported by a hazard zoning map made available by the Environment Agency that is also defined by flood probabilities. In the Netherlands building is only regulated for those unprotected areas where the discharge capacity may be jeopardised. Otherwise, development is at risk which seems to be a sufficient incentive to not or rarely develop there. However, all of these examples relate to frequently flooded areas, generally in unprotected floodplain areas. To our knowledge, nowhere is there a policy in place related to flood hazard zoning in protected areas. The FFH and FDH map may support discussions on developing such a policy, however.

\section{Conclusions}

There is a need to have spatial information on hazards available in support of flood risk management planning. In particular, spatial planning may prevent a further increase in flood risks due to a steadily increasing vulnerability. To inform spatial planning it often does not suffice to map only one hazard parameter, whereas many maps or maps combining more than one hazard parameter are difficult to interpret. By the generic approach which we developed, we were first and foremost able to combine all relevant flood parameters into one map of flood damage hazard and one map of flood fatality hazard. This resulted in maps that are easy to interpret and that are also comprehensive representations of flood hazard, much more than what has so far been achieved by any GIS-based overlay procedure based on single parameter maps.

These comprehensive maps of flood hazard could be achieved because we applied standard and validated damage and mortality functions and multiply the damage factors and mortalities from these functions with the flood probability to obtain the expected annual flood damage factor, or expected annual probability of death due to a flooding. This method allows assessing hazards for different flood sources and different kinds of areas in the same units so that the respective outcomes may be added up to achieve comprehensive flood hazard maps for all flood types together. This is the second advantage of our approach.

Finally, because our approach to define and map flood fatality hazard and flood damage hazard is based on methods and formulae generally applied in quantitative flood risk analyses, we feel we have contributed to a further closing of the gap between quantitative risk analysis and hazard mapping on behalf of spatial planning. The relationship between the definitions of flood hazard and flood risk has become even tighter through this approach, whereas their respective representation in quantitative terms is as close as possible.

Edited by: B. Merz

Reviewed by: two anonymous referees

\section{References}

ABCB: Construction of Buildings in Flood Hazard Areas. Standard Version 2012.2. Australian Government and States and Territories of Australia, Canberra, Australia, 2012.

Beckers, J., De Bruijn, K. M., and Riedstra, R.: Life safety criteria for flood protection standards, in: Floods: From Risk to Opportunity (IAHS Publ. 357), 21-25, 2012.

De Bruijn, K. M. and Klijn, F.: Risky places in the Netherlands: a first approximation for floods, J. Flood Risk Manage., 2, 58-67, 2009.

De Bruijn, K. M. and Slager, K.: Mortality functions in the flood impact module. Sensitivity analysis and discussion. Project 1207814.005, Deltares, Delft, The Netherlands, 2013

Delta Committee: Working together with water. A vital country builds its future, The Hague, The Netherlands, 2008 (in Dutch).

de Moel, H., van Alphen, J., and Aerts, J. C. J. H.: Flood maps in Europe - methods, availability and use, Nat. Hazards Earth Syst. Sci., 9, 289-301, doi:10.5194/nhess-9-289-2009, 2009.

Di Mauro, M. and De Bruijn, K. M.: Application and validation of mortality functions to assess the consequences of flooding to 
people, J. Flood Risk Manage., 5, 92-110, doi:10.1111/j.1753318X.2011.01131.x, 2012.

Di Mauro, M., De Bruijn, K. M., and Meloni, M.: Quantitative methods for estimating flood fatalities: towards the introduction of loss of life estimation in the assessment of flood risk, Nat. Hazards, 63, 1083-1113, doi:10.1007/s11069-012-0207-4, 2012.

EEA: Climate change, impacts and vulnerability in Europe 2012. An indicator-based report, Denmark, 300 p., doi:10.2800/66071, 2012.

EXCIMAP (a European exchange circle on flood mapping): Handbook on good practices for flood mapping in Europe, edited by: Martini, F. and Loat, R., available at: www.ec.europa.eu/ environment/water/flood_risk/flood_atlas, 2007a.

EXCIMAP: Atlas of Flood Maps. Examples from 19 European countries, USA and Japan, 2007b.

FEMA: HAZUS-MH MR4 Technical Manual, USA, available at: http://www.fema.gov/media-library-data/ 20130726-1715-25045-5075/hazus_mr4_flood_tech_manual. pdf, 2009.

HR Wallingford, FHRC and Risk \& Policy Analysts: Flood risks to people phase 2 . The flood risks to people methodology. Flood and Coastal defence R\&D programme, London, UK, DEFRA, 2006.

IPCC: Summary for Policymakers, in: Managing the Risks of Extreme Events and Disasters to Advance Climate Change Adaptation, edited by: Field, C. B., Barros, V., Stocker, T. F., Qin, D., Dokken, D. J., Ebi, K. L., Mastrandrea, M. D., Mach K. J., Plattner, G.-K., Allen, S. K., Tignor, M., and Midgley, P. M., A Special Report of Working Groups I and II of the Intergovernmental Panel on Climate Change, Cambridge University Press, Cambridge, UK, and New York, NY, USA, 1-19, 2012.

Jongejan, R. B., Stefess, H., Roode, N., ter Horst, W., and Maaskant, B.: The VNK2 project: a detailed, large-scale quantitative flood risk analysis for the Netherlands. Proceedings of the 5th International Conference on Flood Management (ICFM5), 27-29 September 2011, Tokyo-Japan, 2011.

Jonkman, S. N.: Loss of life estimation in flood risk assessment, Theory and applications, $\mathrm{PhD}$ thesis, TU Delft, Delft, The Netherlands, 2007.

Klijn, F., De Bruijn, K. M., Knoop, J., and Kwadijk, J.: Assessment of the Netherlands' Flood Risk Management Policy Under Global Change, Ambio, 41, 180-192, doi:10.1007/s13280-0110193-x, 2012.

Kok, M., Huizinga, H. J., Vrouwenvelder, A. C., and Van den Braak, W. E. M.: Standaardmethode 2005. Schade en slachtoffers als gevolg van overstromingen, Rapport 999.10, HKV Lijn in Water, Lelystad, the Netherlands, 2005 (in Dutch).
Kreibich, H., Seifert, I., Merz, B., and Thieken, A.: Development of FLEMOcs - A new model for the estimation of flood losses in companies, Hydrol. Sci. J., 55, 1302-1313, 2010.

Maaskant, B., Jonkman, S. N., and Kok, M.: Analyse slachtofferaantallen VNK-2 en voorstellen voor aanpassingen van slachtofferfuncties, HKV Lijn in Water Rapport PR1669.10, Delft, The Netherlands, 2009a (in Dutch).

Maaskant, B., Kolen, B., Jongejan, R., Jonkman, S., and Kok, M.: Evacuatieschattingen Nederland. Rapport PR1718.10. HKV Lijn in Water, Delft, The Netherlands, 2009b (in Dutch).

Penning-Rowsell, E., Floyd, P., Ramsbottom, D., and Surendran, S.: Estimating injury and loss of life in floods, Nat. Hazards, 36, 43-64, 2005.

PBL: Overstromingsrisicozonering in Nederland. Hoe in de ruimtelijke ordening met overstromingsrisico's kan worden omgegaan, Den Haag/Bilthoven, 2009 (in Dutch).

Samuels, P., Gouldby, B., Klijn, F., Messner, F., Van Os, A., Sayers, P., Schanze, J., and Udale-Clark, H.: Language of Risk Project Definitions, 2nd Edn., EU Floodsite Report T32-04-01, HR Wallingford, UK, 2009.

Slager, K. and Van der Doef, M.: Handboek Overstromingsrisico's op de kaart. Over de methode van kaartproductie voor kaarten op risicokaart.nl, Projectnumber 1209425, Deltares, Delft, The Netherlands, 2014 (in Dutch)

Van de Pas, B., Slager, K., de Bruijn, K. M., Klijn, F., and Pieterse, N.: Overstromingsrisicozonering, Fase 1 en 2: Het identificeren van overstromingsgevaarzones en het ontwikkelen van een methode, Deltares en Planbureau voor de Leefomgeving, Delft, 2012.

Van der Most, H. and Slootjes, N. (Eds.): Technisch inhoudelijke uitwerking van eisen aan primaire keringen. Hoofdrapport, Deltaprogramma, Deelprogramma Veiligheid, Versie DPV2.2 definitief, p. 46, 2014.

VNK2 Project Office: Flood risk in the Netherlands VNK2: The method in brief. Technical background, Utrecht, The Netherlands, p. 64, available at: http://www.helpdeskwater. nl/onderwerpen/waterveiligheid/programma' - projecten/ veiligheid-nederland/english/flood-risk-the/, 2012.

Wagenaar, D. J., de Bruijn, K. M., Bouwer, L. M., and De Moel, H.: Uncertainty in flood damage estimates and its potential effect on investment decisions, Nat. Hazards Earth Syst. Sci. Discuss., 3, 607-640, doi:10.5194/nhessd-3-607-2015, 2015. 